\title{
Demography of Children and its Implications on Government Planning and Policies: Periscoping Enugu State
}

\author{
Dr. A.T Aduma ${ }^{1^{*}}$, Prof. Emma E.O. Chukwuemeka ${ }^{2}$ \\ ${ }^{1}$ Department of Public Administration, Enugu State University of Science and Technology, Enugu \\ ${ }^{2}$ Department of Public Administration, Nnamdi Azikiwe University Awka Nigeria
}

*Corresponding Author: Dr. A.T Aduma, Department of Public Administration, Enugu State University of Science and Technology, Enugu, Nigeria

\begin{abstract}
Birth registration affords every child the opportunity to be captured in the birth data base and the child's nationality established. It affords the government the opportunity also to know the demography of children in a given country which helps them to plan towards children friendly policies. This study investigates therefore the level of child birth registration accomplishment in Enugu State Nigeria and how that will help government's financial planning and policies concerning children in the state. Survey research design was used to accomplish this task. Selected health centers across the three senatorial zones of the state were visited and birth registration data collected from their records. Questionnaire, face-to-face interview and focus group discussion were tools used for data collection. The senior staff of the Ministry of Health Enugu State and Planning managers of the Health centers were interviewed with a view to eliciting data from them. Two hypotheses were formulated as a guide to the study and tested using Pearson Moment Correlation coefficient Analysis. With the support of hospital records, records from National Bureau of Statistics alongside the result of the hypotheses tested, the study revealed that there is low registration of birth in Enugu State which ultimately affects government's ability to plan accurately towards the welfare of children in the state. The paper recommends a bio-data of birth that links all hospitals with the Ministry of Health and National Population Commission to keep track of birth registration in the state. This will help government to formulate child friendly policies based on accurate data of children related demography.
\end{abstract}

Keywords: Demography, Policy, Planning, Child Birth

\section{INTRODUCTION}

Population changes have the capacity of changing economic and social development plans of government. Government policy makers and planners around the world use population projections to gauge future demand for food, water, energy, and services, and to forecast future demographic characteristics. Population projections can alert policymakers to major trends that may affect policies that can be adapted for various projection scenarios (Population Reference Bureau, 2001).

Many countries especially transition economies are facing difficult times and need proper planning to get policies that will pull them out of their economic quagmire. An aspect of this planning is child birth registration. Birth registration is a "fundamental right that affords children the opportunity to be documented and establish their nationality" (Makinde et al, 2016, p.316).

Unfortunately, an estimated 230 million children worldwide have never had their births registered (Bambas, 2005; Bequele, 2005; Cappa et al; 2014; UNICEF, 2013) and governments are handicapped in their bid to plan for these children or forecast any aspect of their future. Africa is worse in this perspective. Bequele (2005), Mikkelseu et al (2015), UNICEF (2013) noted that Africa lags behind in the registration of births though better than Asia.

Child or Civil registration is defined as the universal, continuous, permanent and compulsory recording of vital events provided through decree or regulation in accordance with the legal requirements in a country (World Health Organization \& World Bank, 2014). The birth of a child is one of the important events routinely recorded in a Civil Registration System (CRS) (United Nations, 2001; World Health Organization, 2008). Many countries including Nigeria are signatories to the Convention on the Rights of the Child, which identifies birth registration as a child's right (Makinde 
et al, 2016). However, compliance with birth registration is still below 50\% in Sub-Saharan Africa and South Asia, 25 years after the Convention on the Rights of the Child (CRC) (Cappa et al; 2014; UNICEF, 2014). The CRC is an international treaty comprising 54 articles developed in 1989 to recognize the rights of children. It is regarded as the most widely and rapidly ratified human rights treaty in history (UNICEF, 2014). The right of children to have their births registered is the seventh article of the CRC (Makinde et al, 2016).

The importance of birth registration cannot be undervalued. Birth statistics are a significant source of data for governments in planning and provision of policies that cater for the welfare of the child. Birth registration is an important source of data for planning for social services such as schools, housing, and security. Effective birth registration over time can help in determining the rate of progress and the likelihood of meeting national and global targets (Makinde et al, 2016).

However, Makinde et al (2016) postulate that Nigeria has struggled to ensure compliance with birth registration, with uncertainties as to the level of progress that has been made. No government can plan and execute policies effectively without knowing the demography of its population. To avoid child poverty and achieve the millennium development goals, high level of civil registration must be attained. This paper assesses the demography of children and its implications on government planning and policies, periscoping Enugu State.

\subsection{Problem Statement}

Demography is usually seen as the study of human populations-their size, growth, density and distribution-and statistics regarding birth, marriage, disease and death (Leone, 2010). Demographics are integrated into policy and planning processes and are of key importance to development (Nugent and Seligman, 2008). However, there is the problem of data quality. Most third world countries especially in Africa are plagued with issues of obsolete technology. Births, death and migration that occur in hinter lands and in some cases in the cities are not adequately captured because of lack or inadequate technology to do so. In that regard, in Nigeria according to UNICEF (2007), about 70\% of the 5 million children born annually are not being registered at birth. They have no birth certificate and in legal terms, they do not exist. Their right to an identity, name and nationality is denied and their access to basic services is threatened.

There are further identified challenges associated with fluent registration of births. These challenges include insufficient number of registration centers in the country, limited financial support for birth registration processes, lack of awareness of the importance of birth registration as a human right, ignorance and illiteracy of the rural men and women on the importance of birth registration, decline of women's access to maternity centers because of increased poverty and high medical costs, distance to birth registration centers due to bad roads or non availability of public transport for those in rural areas, lack of effective registration infrastructures and low level of awareness of current legislation (UNICEF, 2007, p.2). It is against this background that we draw the objectives of our study.

\subsection{Objectives of the Study}

The general objective of the study is to determine the demography of children in Nigeria and its implications on government planning and policies. The specific objectives include:

- To investigate the level of child birth registration accomplishment in Enugu State.

- To assess the challenges of child birth registration in Enugu State.

- To proffer solutions to these challenges.

\section{LITERATURE REVIEW}

\subsection{Conceptual Framework}

Birth registration is the first step towards recognizing a child's inalienable right as a human being (UNICEF, 2007). Makinde et al (2016) assert that birth registration is a fundamental right that affords children the opportunity to be documented and establish their nationality. Birth or civil registration is said to be the universal, continuous, permanent and compulsory recording of vital events provided through regulation in compliance with the legal requirements in a country (World Health Organization and World Bank, 2014). 
The Convention on the Rights of the child as captured by State of Nigerian Children Report (2015) states that every child has the right to a name and a nationality and the right to protection from being deprived of his or her identity. Birth registration, state of the Nigerian Children Report (2015) postulate is a fundamental means of securing these rights for children. It confers identity on the child; it identifies the parents, the nationality and confers rights and protection on the child. Hence nonregistration of the child's birth infringes on his/her right to protection and many other benefits (State of the Nigerian Children Report, 2015).

In her own narrative, Wilmott- Harrop $(2015$, p.1) maintains that "birth certificate is itself a human right-the right to identity-as well as being fundamental to the realization of a number of other rights such as providing access to education, healthcare, and voting for example". A birth certificate is also protective against the abuse of rights. If a child has a birth certificate then their life and age are documented and they are less vulnerable to exploitation such as human trafficking and child marriage (Wilmott-Harrop, 2015). Data from birth registration and indeed other aspects of civil registration are very critical in government planning and accountability to the citizens (Wilmott-Harrop, 2015).

\section{CHILD BIRTH ACCOMPLISHMENTS IN NIGERIA}

A research report sponsored by Safe the children (Nigeria Office) titled "Children left behind", captured child birth accomplishments in Nigeria. The report stated that the national registration average was about 30 percent. The highest recorded per state was 66 percent in Osun State while the lowest was 3 percent in Zamfara State. This shows a definite north-south variation in birth registration. Majority of the southern states recorded birth registration above the national average while majority of the northern states recorded birth registration below the national average (state of the Nigerian Children, 2015). Out of the 19 states and FCT (Abuja) that scored above national average, only Kwara, Kogi, Adamawa, Katsina and FCT (Abuja) are in the North. On the contrary, out of the 17 states which scored below the national average all except Bayelsa and Cross River States are in the north (state of the Nigerian Children, 2015).

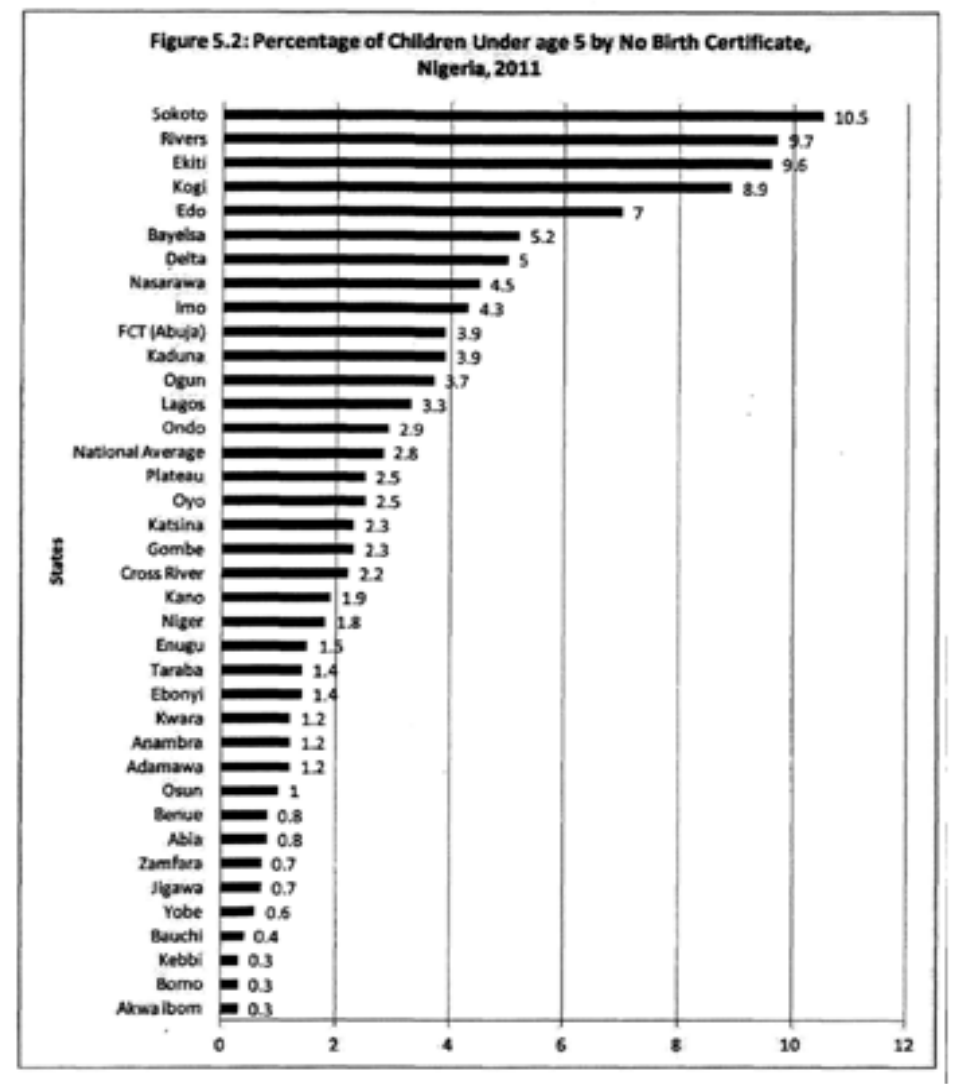

Figure1. Shows the percentage of children without birth certificates. Twenty three (23) states and FCT (Abuja) had children without birth certificates below the national average of about 3 percent while the remaining thirteen (13) states of the federation had above the national average.

Source: State of the Nigerian Children, 2015. 


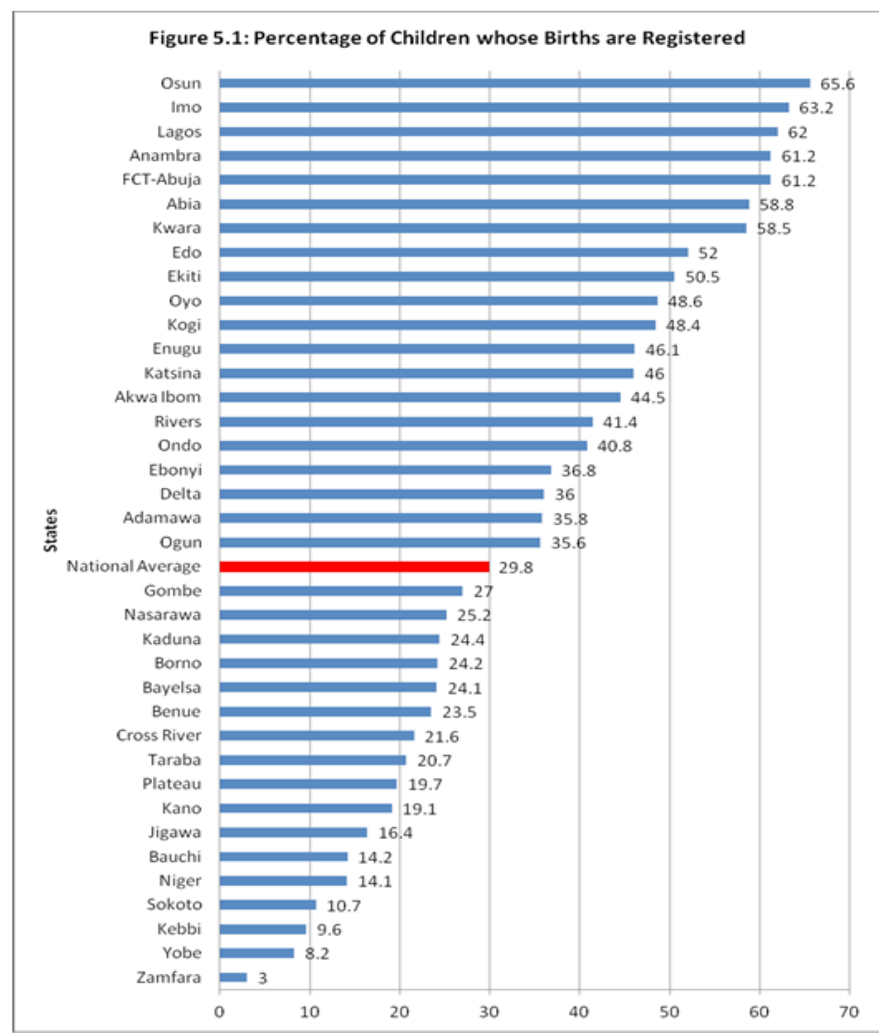

Figure2. Shows the percentage of children whose births were captured and registered. The figure showed that the rate of birth registration increased in southern states against the northern states

Source: State of the Nigerian Children, 2015.

\section{AIM AND HYPOTHESES}

Lifting children out of poverty and formulation of children friendly policies are at the heart of Nigerian government's plans. But that cannot be achieved without adequate knowledge of the population of children. Government of Nigeria as signatory to the Convention on the Rights of the Child which recognizes birth registration as an alienable right of every child seeks to implement the treaty. It is our aim in this research study to find out the level of child birth registration accomplishment in Enugu State and to assess the challenges of child birth registration in the state. It is in that context that we propose the following hypotheses:

- There is insignificant level of child birth registration in Enugu State.

- There is a correlation between illiteracy and child birth registration in Enugu State.

\section{Methodology}

\subsection{Participants}

The research was carried out at selected health centers in the three senatorial zones of Enugu State. Participants in this study consisted of staff of the health centers. The total participants were 790. Because of the large population, the participants were reduced to a researchable size through Yamane formula thus:

$$
\begin{aligned}
& \mathrm{n}=\frac{N}{1+N(e)^{2}} \\
& \mathrm{n}=\frac{790}{1+790(0.05)^{2}} \\
& \mathrm{n}=\frac{790}{1+790(0.0025)^{2}} \\
& \mathrm{n}=\frac{790}{1+1.975}
\end{aligned}
$$


$\mathrm{n}=\frac{790}{2.975}$

$=265($ Sample Size $)$

Participants for this study were therefore 265 staff of the health facilities selected through random sampling. However, 252 questionnaires were filled appropriately and used for analysis.

\section{DATA ANALYSiS}

Empirical evidence for this study was obtained through the use of questionnaire. Likert scale was used to generate data from the questionnaire. The information was put in a weighted scale with numerical values attached to them in the questionnaire as follows: Strongly Agree $=5$, Agree $=4$, Undecided $=3$, Disagree $=2$, Strongly Disagree $=1$. The data was analyzed using descriptive and inferential statistics. The descriptive statistics involved computation of means and standard deviations from the responses of the respondents to the questionnaire items. The decision rule was to accept any item that has a mean score of 2.15650 and above. The hypotheses were tested using regression analysis.

\section{DATA PRESEnTATION AND ANALYSIS}

Let $\mathrm{x}$ represents illiteracy level

While y represents child birth registration

For hypothesis One

$X=124,91,10,13,14=252$

$\mathrm{Y}=116,74,35,10,17=252$

For hypothesis Two

$X=114,72,33,23,10=252$

$\mathrm{Y}=134,82,26,6,4=252$

\subsection{Test of Hypothesis One}

There is insignificant level of child birth registration in Enugu State.

\section{Correlations}

\begin{tabular}{|l|l|l|l|}
\hline & & \multicolumn{1}{c|}{ Child Birth } & \multicolumn{1}{c|}{ Child Birth Registration } \\
\hline $\mathrm{X}$ & Pearson Correlation & 1 & $.965(* *)$ \\
\hline & Sig. (2-tailed) & & .008 \\
\hline & N & 5 & 5 \\
\hline Y & Pearson Correlation & $.965(* *)$ & 1 \\
\hline & Sig. (2-tailed) & .008 & \\
\hline & N & 5 & 5 \\
\hline
\end{tabular}

** Correlation is significant at the 0.01 level (2-tailed).

From 2 the correlation table (table 4.6), the correlation value of $9.56 \%$ is a relationship that is very strong. The p-value of the variable is greater than the level of significance of $1 \%(1.000>0.05)$. This shows that there is positive and strong correlation between the level of child birth registration, which is also significant at the 0.01 level (2-tailed). This means that we uphold the alternate hypothesis. This implies that there is insignificant level of child birth registration in Enugu State.

\subsection{Test of Hypothesis Two}

There is a correlation between illiteracy and child birth registration in Enugu State.

Correlations

\begin{tabular}{|l|l|l|l|}
\hline & & Child Birth Registration & Level of Illiteracy \\
\hline Child Birth & Pearson Correlation & 1 & $.995(* *)$ \\
\hline & Sig. (2-tailed) & & .000 \\
\hline & N & 5 & 5 \\
\hline Level of Illiteracy & Pearson Correlation & $.995\left(^{* *}\right)$ & 1 \\
\hline & Sig. (2-tailed) & .000 & \\
\hline & N & 5 & 5 \\
\hline
\end{tabular}

** Correlation is significant at the 0.01 level (2-tailed). 
From the correlation table (table 4.6), the correlation value of $9.95 \%$ is a relationship that is very strong. The p-value of the variable is greater than the level of significance of $1 \%(1.000>0.05)$. This shows that there is a strong and correlation between illiteracy and child birth registration, which is also significant at the 0.01 level (2-tailed).This means that we uphold the null hypothesis. This implies that there is a significant relationship between illiteracy and child birth registration in Enugu state.

\section{DISCUSSION}

Birth registration is a sine qua non in any state that wants to plan effectively and develop. Nigeria is lagging behind in child birth registration but some states are doing better than others. Enugu state is among the states that are measuring well in child birth registration. There are numerous benefits of birth registration and borrowing from a UNICEF (2010) narrative, birth registration ensures that children have access to health care services and immunization; it effectively counters the problem of girls who do not have proof of age being forced into marriage before they are legally eligible; it ensures that children in conflict with the law are given special protection, and are not treated (legally and practically) as adults; it ensures that children are not recruited into armed forces and groups before they are legally eligible; it secures the child's right to nationality at the time of birth or at a later stage; it helps identify children who are trafficked, and permits their repatriation and reunification with family members; it assures the right to a passport and the right to vote, but also useful for opening a bank account or finding employment and it ensures that children enroll in school at the appropriate age.

Birth registration ensures acquisition of a birth certificate-an official document that brings recognition to a child's identity. The data obtained in the registration is used by government for development planning, formulation of state policies and allocations to different sectors of government.

However, birth registration does not mean registration of births in maternity homes. It means registration of birth with an agency of government known as National Population Commission. They are saddled with the task of recording births and making the data available to the government. They are domiciled in all registered maternity homes across the country.

Child poverty can be eradicated only when adequate plan for children are put in place by government and they can only do so when they have data to work with. When adequate birth registration measures are put in place, only then will no child be left behind.

\section{RECOMMENDATIONS}

This paper puts up the following strategies towards promoting a better and more efficient birth registration in Enugu State and Nigeria.

- Education and creation of awareness to parents especially those in rural background.

- Registration of all maternity homes with the Ministry of Health with a data base that links National Population Commission.

- Enabling law that makes birth registration a condition for enrollment in schools, admission of vaccines in hospitals and other social services by the government.

- National Population Commission training field officers that include Monitoring \& Evaluation $(\mathrm{M} \& \mathrm{E})$ officers that will track births in hospitals \& maternities.

\section{CONCLUSION}

There is a need to register a child's birth to secure the child's identity, nationality and future. With the captured data, government can plan for adequate healthcare, education and other social responsibilities that will ensure the child's continuous existence. Nigeria is averaging a record of about 30 percent in child birth registration of which many states including Enugu State are among the leading states in that regard. However, that figure is well below acceptable global standard in birth registration of children. Government should therefore up their game by registering and linking all hospitals and maternity homes with Ministry of Health and National Population Commission agency to keep track of birth registration in the state. This will help government formulate child friendly policies based on accurate data of child demography. 


\section{REFERENCES}

[1] Bambas, L. (2005) Integrating equity into health information systems: A human rights approach to health and information. PLOSMed, 2(4).

[2] Bequele, A. (2005) Universal birth registration: The challenge in Africa. Retrieved on 15 July, 2018 from http://www.riatt-esa.org/sites/default/files/get_file_8f4dle7.pdf.

[3] Cappa, C., Gregson, K., Wardlaw, T., and Bissel, S. (2014) Birth registration: A child's passport to protection. The Lancet Global Health 2(2): 67-68.

[4] Leone, T. (2010) How can demography inform health policy? Health Economics, Policy and Law, 5, 1-11.

[5] Makinde, O.A., Olapeju, B., Ogbuoji, O. \& Babalola, S. (2016) Trends in the completeness of birth registration in Nigeria: 2002-2010. Demographic Research, 35(12): 315-338.

[6] Mikkelsen, L., Phillips, D.E., abouzahr, C., Setel, P.W., de Savigny, D., Lozano, R., and Lopez, A.D. (2015) A global assessment of civil registration and vital statistics systems: Monitoring data quality and progress. The Lancet, 386:1395-1406. doi:10.1016/So140-6736(15) 60171-4.

[7] Nugent, R., \& Seligman, B. (2008) How demographic change affects development. Demographics and Development in the $21^{\text {st }}$ Century Initiative Technical Background Paper.

[8] Population Reference Bureau (2001) Understanding and using population projections. Retrieved on 13 July, 2018 from https:/www.prb.org/understandingandusingpopulationprojections/

[9] State of the Nigerian Children Report (2015) State of Nigerian Children 2015: Children left behind in Nigeria. Retrieved on 15 July, 2018 from http://nigeria.savethechildren.net/.../nigeria.savethechildren.../ state $\% 20$ of $\% 20$ Nigeria...

[10] UNICEF (2007) Factsheet on birth registration in Nigeria. Retrieved on 13 July, 2018 from https//www.unicef.org/wcaro/WCARO_Nigeria_Factsheets_BirthRegisrtation.pdf.

[11] UNICEF (2010) UNICEF Nigeria Fact Sheet: Birth registration in Nigeria. Retrieved on 22 July, 2018 from ng_media_birth_registration_fact_sheet_July_2010.pdf.

[12] UNICEF (2013) Every child's birth right: Inequities and trends in birth registration. [electronic resource] Retrieved on 16 July 2018 from http://www.unicef.org/media/files/Embargoed_11_Dec_Birth_ Regisrtation_report_low_res.pdf.

[13] UNICEF (2014) 25 years of the Convention on the Rights of the Child: Is the world a better place for children? [electronic resource] Retrieved on 16 July 2018 from http://www.unicef.org/publications/index _76027.html.

[14] United Nations (2001) Principles and recommendations for a vital statistics system. New York: United Nations Publications. Retrieved on 18 July 2018 from http://unstats.un.org/unsd/publication/seriesM/ SeriesM_19rev2E.pdf

[15] Willmott-Harrop, E. (2015) The first right birth registration in Nigeria. Retrieved on 15 July, 2018 from http://liberty and humanity.com/themes/child-rights/the-first-right-birth-regisrtation-in-nigeria/

[16] World Health Organization (2008) Framework and standards for country health information systems. Retrieved on 18 July, 2018 from http://apps.who.int/iris/hand;e/10665/43972.

[17] World Health Organization and World Bank (2014) Global civil registration and vital statistics: Scaling up investment plan 2015-2024. The World Bank.

Citation: Dr. A.T Aduma, Prof. Emma E.O. Chukwuemeka. "Demography of Children and its Implications on Government Planning and Policies: Periscoping Enugu State". International Journal of Research in Tourism and Hospitality (IJRTH), vol 5, no. 1, 2019, pp. 23-29. doi: http://dx.doi.org/10.20431/24550043.0501004 .

Copyright: (C) 2019 Authors. This is an open-access article distributed under the terms of the Creative Commons Attribution License, which permits unrestricted use, distribution, and reproduction in any medium, 